\title{
Muscular Dystrophy- Facioscapulohumeral Dystrophy - A Rare Autosomal Dominant Disorder
}

\author{
Praveen Kumar Baghel ${ }^{1}$, Rajesh Kumar Kewat², Gaurav Agrawal ${ }^{3}$ \\ ${ }^{1}$ Department of Medicine, SSMC and Sanjay Gandhi Memorial Hospital, Rewa, Madhya Pradesh, India. \\ 2Department of Medicine, SSMC and Sanjay Gandhi Memorial Hospital, Rewa, Madhya Pradesh, India. \\ ${ }^{3}$ Department of Medicine, SSMC and Sanjay Gandhi Memorial Hospital, Rewa, Madhya Pradesh, India.
}

\section{PRESENTATION OF CASE}

A 24-year-old man presented to the Medicine OPD of Sanjay Gandhi Memorial Hospital, Rewa (M.P.), with complaints of weakness of limbs and decrease in muscle mass from past 12 years. He was apparently normal till the age of 8 years, after which, he started developing weakness in the limbs.

Weakness of limbs was insidious in onset and gradually progressive in nature, due to which he had to leave schooling. He noticed that he could not get up from sitting position without support, and was unable to climb stairs. The weakness gradually progressed and currently patient is finding it difficult to even walk. It is associated with difficulty in lifting arms above shoulder, combing hair as well as holding heavy objects. He also has complaints of inability to smile, whistle, hold air in mouth, incomplete closure of eyes as well as difficulty in chewing. There was no history of any distal muscle weakness, numbness, abnormal body movement, dysphagia, dysarthria, nasal regurgitation, chest pain, palpitation, breathlessness, bladder and bowel involvement. He is also having no history of any recurrent hospital admission.

On examination, Patient was comfortable at rest with a pulse rate of 82 beats/minute and blood pressure of $130 / 80 \mathrm{mmHg}$ and respiratory rate was $18 /$ minute and regular in rhythm. There were no signs of pallor, icterus, clubbing, cyanosis, raised jugular venous pressure or pedal oedema. He was conscious and oriented and other higher mental functions were normal. Examination of all cranial nerves were within normal limits.

On motor examination, Patient was having atrophy of muscles of neck, chest, arm and thigh. He was also having prominent clavicle which lies horizontal. He was also having pectus excavatum. On abduction of both arms, there was bilateral prominence of trapezius muscle. He was also having bilateral prominent scapula and he was unable to push the arms against the wall. He was able to abduct both the arms up to angle of 90 degree but unable to do over head abduction of both arms. He was also unable to smile, hold air in mouth, and finds difficulty in whistling. He was unable to lift the head in lying down position. He was also having atrophy in arms and legs. In the wrist and ankle, tone and deep tendon reflexes were normal while in shoulder, elbow and knee, deep tendon reflexes were absent. He was also having lumbar lordosis with toe-walking. He was having reduced power in both upper and lower limbs. Other systemic examination were essentially normal.

Facioscapulohumeral muscular dystrophy (FSHD) is the third most common form of hereditary myopathy with a prevalence of 1 in 20.000.[1] It is a complex genetic disorder characterised in most cases by slowly progressive muscle weakness involving the fascial, scapular, upper arm, lower leg and hip girdle muscle usually with asymmetric involvement. The disease is characterized by progressive atrophy and weakness of a highly selective set of muscle groups.
Corresponding Author: Dr. Rajesh Kumar Kewat, Room No. 24, PG, Boys Hostel, SSMC and SGMH, Rewa-486001, Madhya Pradesh, India.

E-mail: drrajeshkewat.mp@gmail.com

DOI: $10.14260 / \mathrm{jemds} / 2020 / 353$

Financial or Other Competing Interests: None.

How to Cite This Article:

Baghel PK, Kewat RK, Agrawal G. Muscular dystrophy- facioscapulohumeral dystrophy- a rare autosomal dominant disorder. J. Evolution Med. Dent. Sci. 2020;9(20):1616-1618, DOI: $10.14260 / \mathrm{jemds} / 2020 / 353$

Submission 18-03-2020,

Peer Review 01-05-2020,

Acceptance 08-05-2020,

Published 18-05-2020.

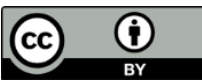



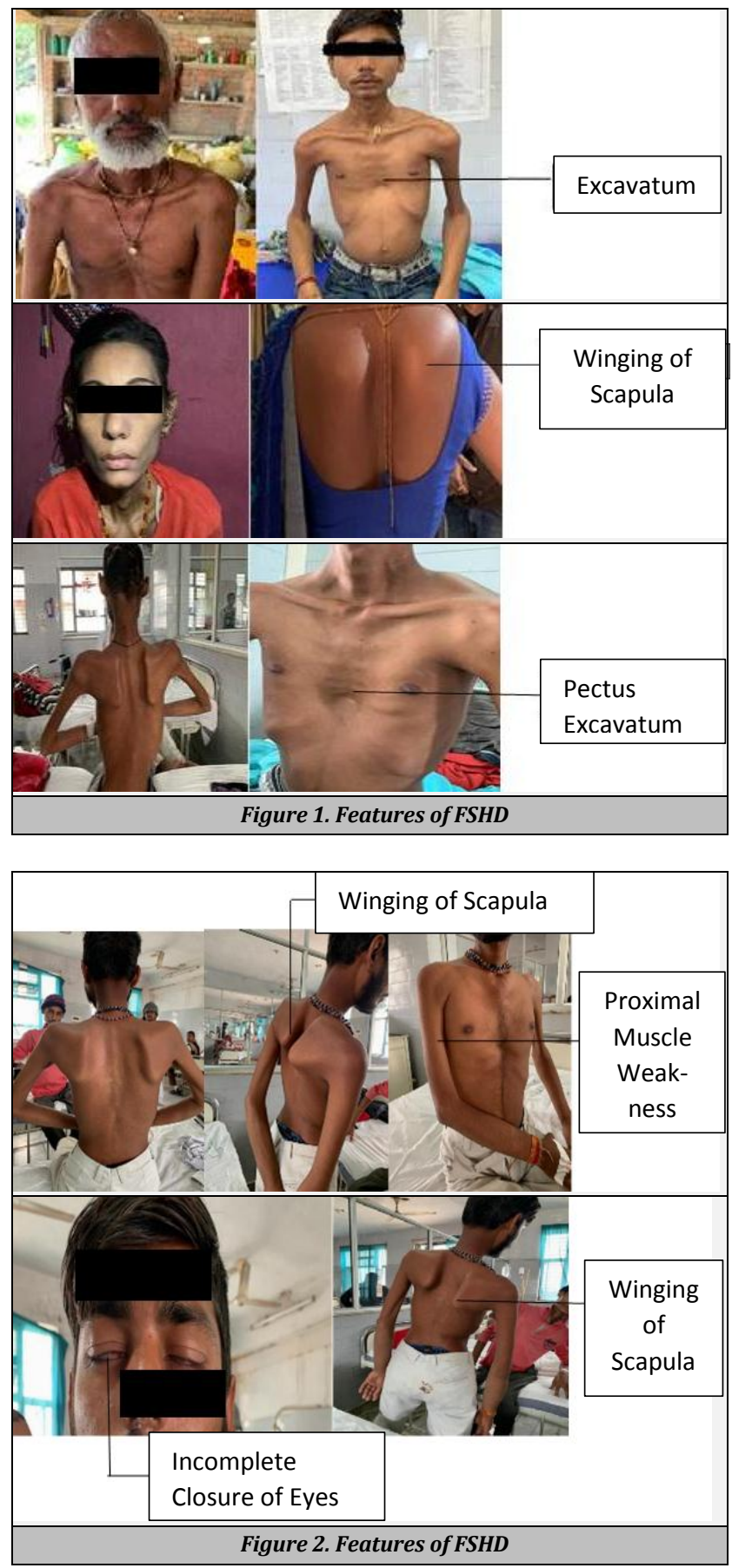

\section{PATHOLOGICAL DISCUSSION}

His haemoglobin was $14.9 \mathrm{gm} / \mathrm{dL}$ with total leucocyte count 6000 with differential count 70/24/4/2. Normal platelet count 1.5 lakh. Blood sugar was $119 \mathrm{mg} / \mathrm{dL}$ with normal liver and renal function test. His ESR was $12 \mathrm{~mm}$. human immunodeficiency virus testing by enzyme linked immunosorbent assay was negative.

ECG was suggestive of right bundle branch block morphology with normal echo cardiography and chest x-ray suggestive of rib cage deformity.

Ultrasonography was suggestive of no abnormal finding. Creatine phosphokinase level is normal. Muscle biopsy showed variation in fibre size with mild increase in perimysial and endomysial connective tissue and focal adipose tissue infiltration. Enzyme histochemistry shows normal fibre type grouping. Immunohistochemistry for dystrophin 1, 2, 3, merosin (alpha laminin 2), emerin, alpha, beta, gamma sarcoglycan and dysferlin show normal staining pattern. Features are compatible with facioscapulohumeral muscular dystrophy.

The most probable cause of FSHD is inappropriate expression of the double homeobox protein 4 gene (DUX4).[2,3] The DUX4 gene lies within each unit of a macrosatellite array known as D4Z4, located in the $4 \mathrm{q} 35$ region. The DUX4 gene is normally expressed in germ line tissue and is epigenetically repressed in somatic cells. [3]

Release of DUX4 repression only occurs in the context of a permissive genetic background. Before the finding of D4Z4 reduced alleles (DRA) at 4q35, which have been considered pathognomonic for disease, the diagnosis and counseling of FSHD families were entirely based on clinical evidence and family history. Over the years, DNA testing for FSHD has been considered highly sensitive and specific. $[4,5]$

In approximately 95 percent of patients with FSHD, the disorder is causally related to a short repeat array that remains after deletion of an integral number of tandemly arrayed $3.3 \mathrm{~kb}$ repeat units (called D4Z4) in the $4 \mathrm{q} 35$ region. [6,7] The number of D4Z4 repeat units in the general population varies from 11 to 100. In most patients with FSHD, one D4Z4 allele is contracted ( 1 to 10 repeat units; EcoRI fragments $<38$ $\mathrm{kb}$; EcoRI/BlnI fragments $<35 \mathrm{~kb}$ ), and the other D4Z4 allele has the normal number (11 to 100 repeat units), a condition termed FSHD1. Contracted D4Z4 repeat arrays have been associated with DNA hypomethylation and a reduction of histone 3 lysine 9 trimethylation and heterochromatin protein

1 gamma markers, favouring a more relaxed chromatin structure.[8,9] Thus, D4Z4 contractions may affect adjacent gene expression by altering chromatin configuration.

Fewer than 5 percent of patients with FSHD have no contracted D4Z4 repeat array but show DNA hypomethylation on both normal D4Z4 alleles, [6] a condition termed FSHD2. The phenotype of patients with FSHD2 appears to be clinically indistinguishable from those with FSHD1.[10] There is evidence that DUX4 expression is up- regulated in patients with FSHD,[11] and FSHD muscle cells produce mRNA that encodes the full length DUX4 protein.[12] Synthesis of DUX4 transcripts and protein is toxic in muscle cells.

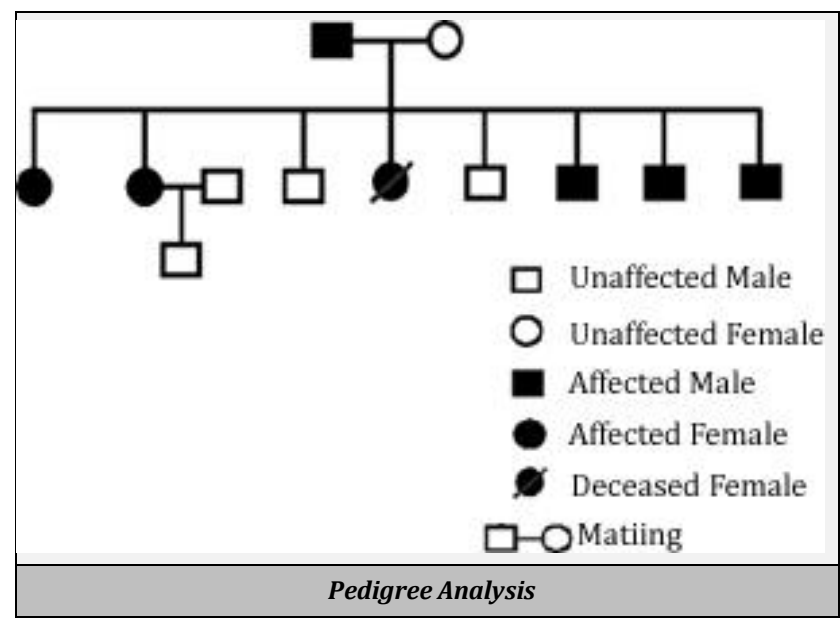


Patient had 10 members in his family in which 3 daughter and 5 sons and in his family members father is affected and among sibling 3 daughters and 3 sons were affected while his mother and rest two brothers are normal in which one of his sister died. All the affected individuals are wheel chair bound except one of his brothers.

\section{CONCLUSIONS}

Facioscapulohumeral muscular dystrophy is a diagnosis of exclusion. Careful history taking, family history, examination, investigation including serum creatine kinase level, muscle biopsy findings are considered for diagnosis.

\section{REFERENCES}

[1] Mostacciuolo ML, Pastorello E, Vazza G, et al. Facioscapulohumeral muscular dystrophy: epidemiological and molecular study in a north-east Italian population sample. Clin Genet 2009;75(6):550-5.

[2] Gabriëls J, Beckers MC, Ding H, et al. Nucleotide sequence of the partially deleted D4Z4 locus in a patient with FSHD identifies a putative gene within each $3.3 \mathrm{~kb}$ element. Gene 1999;236(1):25-32.

[3] Richards M, Coppée F, Thomas $N$, et al. Facioscapulohumeral muscular dystrophy (FSHD): an enigma unravelled? Hum Genet 2012;131(3):325-40.

[4] Upadhyaya M, Maynard J, Rogers MT, et al. Improved molecular diagnosis of facioscapulohumeral muscular dystrophy (FSHD): validation of the differential double digestion for FSHD. J Med Genet 1997;34(6):476-9.
[5] Tawil R, van der Maarel S, Padberg GW, et al. 171 ${ }^{\text {st }}$ ENMC International Workshop: Standards of care and management of facioscapulohumeral muscular dystrophy. Neuromuscul Disord 2010;20(7):471-5.

[6] Van der Maarel SM, Tawil R, Tapscott SJ. Facioscapulohumeral muscular dystrophy and DUX4: breaking the silence. Trends Mol Med 2011;17(5):252-8.

[7] Lebwohl NH. Regarding: Analysis of Scoliosis Research Society (SRS) podium presentations for the last seven years: implications of an SRS Annual Meeting Abstract Registry. Cho W, Kim D, Chen F, Moon S, Chang DG. Spine Deform. $2019 \quad$ Nov; 7(6):845-856. doi:10.1016/j.jspd.2019.04.007. PMID: 31731993. Spine Deform 2020;8(2):349.

[8] Van Overveld PGM, Lemmers RJFL, Sandkuijl LA, et al. Hypomethylation of D4Z4 in 4q-linked and non-4qlinked facioscapulohumeral muscular dystrophy. Nat Genet 2003;35(4):315-7.

[9] Zeng W, De Greef JC, Chen YY, et al. Specific loss of histone H3 lysine 9 trimethylation and HP1gamma/cohesin binding at $\mathrm{D} 4 \mathrm{Z} 4$ repeats is associated with facioscapulohumeral dystrophy (FSHD). PLoS Genet 2009;5(7):e1000559.

[10] De Greef JC, Lemmers RJ, Camaño P, et al. Clinical features of facioscapulohumeral muscular dystrophy 2. Neurology 2010;75(17):1548-54.

[11] Dixit M, Ansseau E, Tassin A, et al. DUX4, a candidate gene of facioscapulohumeral muscular dystrophy, encodes a transcriptional activator of PITX1. Proc Natl Acad Sci USA 2007;104(46):18157-62.

[12] Snider L, Geng LN, Lemmers RJLF, et al. Facioscapulohumeral dystrophy: incomplete suppression of a retrotransposed gene. PLoS Genet 2010;6(10):e1001181. 